\title{
Factors and experiences associated with unscheduled 30-day hospital readmission: A mixed method study
}

Amartya Mukhopadhyay ${ }^{1}{ }_{F R C P}$, Bhuvaneshwari Mohankumar ${ }^{2}{ }_{M P H}$, Lin Siew $\underline{\text { Chong }}{ }^{3}$ MSc , Zoe J-L $\underline{\text { Hildon }}{ }^{4}$ PhD, Bee Choo Tai ${ }^{4}{ }_{P h D}$, Swee Chye Quek ${ }^{3} M D$

\begin{abstract}
Introduction: Analysis of risk factors can pave the way for reducing unscheduled hospital readmissions and improve resource utilisation.

Methods: This was a concurrent nested, mixed method study. Factors associated with patients readmitted within 30 days between 2011 and 2015 at the National University Hospital, Singapore $(\mathrm{N}=104,496)$ were examined. Fifty patients were sampled in 2016 to inform an embedded qualitative study. Narrative interviews explored the periods of readmissions and related experiences, contrasted against those of non-readmitted patients.

Results: Neoplastic disease (odds ratio [OR] 1.91, 95\% confidence interval [CI] 1.70-2.15), number of discharged medications (5 to 10 medications OR 1.21, 95\% CI 1.14-1.29; $\geq 11$ medications OR 1.80, 95\% CI 1.66-1.95) and length of stay $>7$ days (OR 1.46, 95\% CI 1.36-1.58) were most significantly associated with readmissions. Other factors including number of surgical operations, subvention class, number of emergency department visits in the previous year, hospital bill size, gender, age, Charlson comorbidity index and ethnicity were also independently associated with hospital readmissions. Although readmitted and non-readmitted patients shared some common experiences, they reported different psychological reactions to their illnesses and viewed hospital care differently. Negative emotions, feeling of being left out by the healthcare team and perception of ineffective or inappropriate treatment were expressed by readmitted patients.

Conclusion: Patient, hospital and system-related factors were associated with readmissions, which may allow early identification of at-risk patients. Qualitative analysis suggested several areas of improvement in care including greater empowerment and involvement of patients in care and decision making.
\end{abstract}

Ann Acad Med Singap 2021;50:751-64

Keywords: Comorbidity, diagnosis, hospital readmission, qualitative evaluation, socioeconomic factors

\section{INTRODUCTION}

Readmission leads to a greater demand for healthcare services, especially hospital beds, and contributes to the rising healthcare costs. ${ }^{1,2}$ With estimated onethird of the readmissions considered preventable, ${ }^{3}$ early identification of the underlying risk factors can offer better management and discharge planning. ${ }^{4}$ Some risk factors of readmissions related to patient (e.g. age, comorbidities) and hospital (e.g. bed occupancy rate, discharge destination) may be common in different geographical regions; however, many factors including socioeconomic conditions are unique to specific areas. Asian studies are largely limited to elderly patients ${ }^{5}$ or specific conditions. ${ }^{6,7}$ In 2019, the 30-day unplanned readmission rate in Singapore was $18.6 \%$ among patients aged 65 years and older. ${ }^{8}$ Singapore's national and institutional targets were less than $10 \%$ and $11.37 \%$, respectively.

Risk models have been developed using large administrative databases to predict 30-day hospital readmission such as the LACE (L: length of hospital

\footnotetext{
${ }^{1}$ Department of Medicine, National University Hospital, Singapore

${ }^{2}$ Medical affairs, National University Hospital, Singapore

${ }^{3}$ Department of Paediatrics, National University Hospital, Singapore

${ }^{4}$ Saw Swee Hock School of Public Health, National University of Singapore

Correspondence: Dr Bhuvaneshwari Mohankumar, Department of Medical Affairs (Clinical Governance), 1E Kent Ridge Road, NUHS Tower Block Level 6, Singapore 119228.

Email: bhuvaneshwari@nuhs.edu.sg
} 


\section{CLINICAL IMPACT}

\section{What is New}

- This study highlights the importance of both quantitative (patient, hospital, and system-related characteristics) and qualitative (patients' experience) factors associated with hospital readmissions.

- The study covered a general adult hospitalised cohort including surgical patients.

\section{Clinical Implications}

- Early identification of patients with potential risk factors will reduce hospital readmissions.

- The findings support the need in empowering patients and involving them in decision-making on their health matters and disease management.

stay; A: acuity on admission; C: comorbidity; E: emergency department visits) index, ${ }^{9}$ HOSPITAL score $(\mathrm{H}$ : haemoglobin; $\mathrm{O}$ : discharge from an oncology service; S: sodium level at discharge; P: procedure during the index admission; I and T: index type of admission [non-elective versus elective]; A: number of admissions during the past 12 months; L: length of stay), ${ }^{10}$ and risk prediction model. ${ }^{11}$ These models have limited number of variables, which are attractive for administration purposes but have reduced prediction ability (area under curve $0.68-0.71$ ). Indeed, a systematic review that included 26 different risk prediction models concluded that most performed poorly. ${ }^{11}$ Social, environmental, and post-discharge factors contributing significantly to hospital readmissions are not captured in administrative data, and therefore not studied adequately. ${ }^{11}$

Readmitted patients have revealed consistent themes of post-hospital vulnerability. ${ }^{12-14}$ A qualitative study ${ }^{12}$ exploring readmissions among diabetic patients identified several themes that contributed to the readmission risk, including poor health literacy, lack of awareness of medication changes, and post-discharge support. Most of the patients required help with transportation, medications and food, and generally believed that being readmitted was out of their control. ${ }^{12}$ Older readmitted patients were often uninformed about their own care and at times felt unheard and ignored by the healthcare professionals. In some instances, patients affirmed their feelings of not being fully recovered or well enough to go home. ${ }^{15}$
Application of mixed methodology with concurrent analysis of quantitative and qualitative data is likely to improve the understanding of the complex issues associated with readmission but uncommon in literature for general patient population. Our main objective was to identify factors associated with 30-day unscheduled hospital readmission by analysing a large administrative database. We also explored the question of how such experiences were lived, comparing the readmitted and the non-readmitted and cataloguing similarities and differences, in an embedded qualitative study.

\section{METHODS}

The study was conducted at the National University Hospital, Singapore-a 1,200-bed university-affiliated hospital. We adopted a concurrent nested mixed method design. ${ }^{16,17}$ By using both methods, we were able to exploit the strengths of each (quantifying what is known) while redressing inherent weaknesses (qualifying lived experiences and new potential explanations). The study was approved by the National Healthcare Group Domain Specific Review Board (Reference no: 2016/00339). The respective quantitative and qualitative methodologies are described below.

\section{Quantitative methods}

Administrative hospital data involving several systems, including the registration, electronic health records and pharmacy databases, were extracted between January 2011 and December 2015. The sample selection of the quantitative study is shown in Fig. 1. It consisted of inpatients aged $\geq 18$ years at the time of index admission and survived to hospital discharge. We considered patients with first admission during the study period and excluded those whose "first admission" was a readmission from the previous 30 days from 31 December 2010. Using rule of 10 outcome events for each predictor variable tested in a logistic regression model, ${ }^{18}$ the study was sufficiently powered to identify factors associated with readmissions for 104,496 patients.

The administrative data consisted of demographics, discharge status (home or step-down care), subvention category (as a marker of socioeconomic status), diagnoses, comorbidities using Charlson comorbidity index (CCI), surgical operations during the index admission, discharge medications, hospital length of stay (LOS), number of emergency department visits in the past 12 months from the day of index admission, and hospital bill size (before subvention). Age was divided into 4 categories: $18-29,30-49,50-69$ and $\geq 70$ years. 


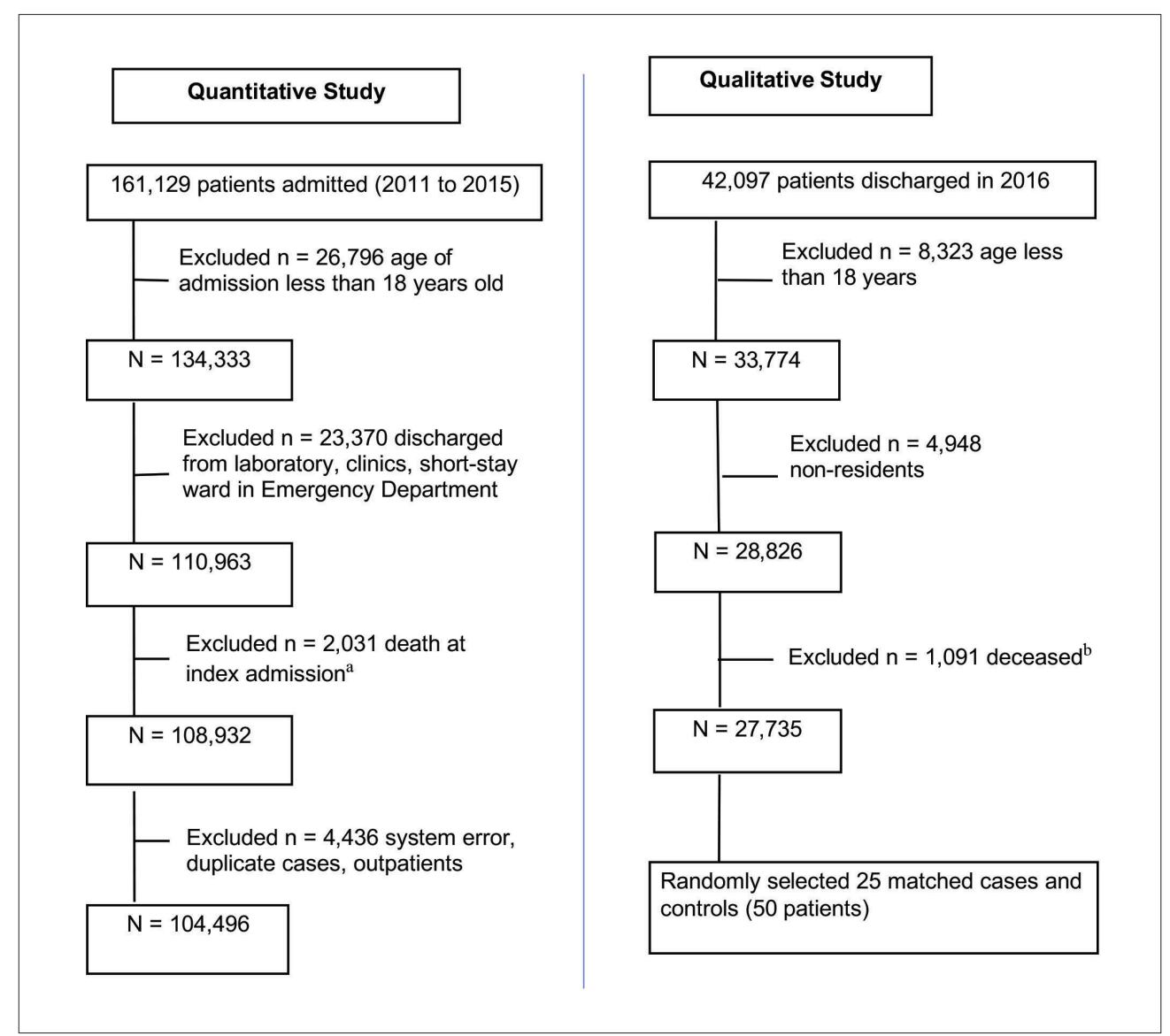

Fig. 1. Schematic diagram of patients included in the respective studies.

a Patients who died during the index admission $(n=2,031)$ were excluded as they had only one admission during the study period and passed away in that admission.

${ }^{\mathrm{b}}$ All the death cases in $2016(\mathrm{n}=1,091)$ were excluded from the qualitative study.

Number of surgical operations was grouped as $0,1,2$ and $\geq 3$. Length of stay was grouped as $1-7$ and $>7$ days. Diagnosis was grouped into 11 broad disease categories: circulatory system, injury/poisoning/external causes of disease, pregnancy/childbirth/puerperium-related, neoplasms/haemopoietic system, digestive system, respiratory system, genitourinary system, nervous system, endocrine/metabolic system, eye/ear disease and others. There were no missing values for all the quantitative variables except number of discharged medications, which had $4.1 \%$ missing value due to incomplete records.

\section{Statistical methods}

The characteristics of patients with and without readmissions were compared using chi-square test. Multivariable logistic regression was carried out to identify factors that were associated with 30-day readmission. Variables or a surrogate thereof that have been shown to predict readmission after extensive literature search, ${ }^{9-11}$ as well as additional variables in the database that were found to be significant at the $5 \%$ level in the bivariate analysis were considered for inclusion in the multivariable analysis. The effect of risk factors was quantified based on the odds ratio (OR) estimate and its associated $95 \%$ confidence interval (CI). The likelihood ratio statistics was used as a measure of importance amongst significant predictors in the multivariable model. The quantitative statistical analyses were conducted using Stata version 15 (StataCorp, College Station, US). All tests were two-sided, with a $P$ value $<0.05$ considered as statistically significant.

\section{Qualitative methods}

The qualitative phase of the study was conducted from January to December 2016; it is described following the consolidated criteria for reporting qualitative studies. ${ }^{19}$

\section{Research team reflexivity}

Qualitative data were collected by team members working as public health practitioners, who are familiar with English and local languages in Singapore 
(Mandarin, Malay or Tamil). Rapport was built over a first telephone contact and during one meeting, and by adjusting for language preferences.

\section{Theoretical framework}

A phenomenological approach was used, ${ }^{20}$ with the emphasis on contrasting lived experiences of readmission within 30 days against single admissions. A comparative thematic analysis was employed to highlight similarities and differences between these groups that were anchored onto topics of interest, as described below.

\section{Participant selection}

The qualitative sample was extracted from a list of patients admitted in 2016, ranking from the most common to least common diagnoses, and classifying them as readmitted or non-readmitted patients within 30 days. Patients were matched by gender, age, ethnicity and primary discharge diagnosis and selected using maximum variation sampling (Table 1). Twenty-five such matched pairs consented to participate. Following obtaining permission from the attending physicians, shortlisted candidates were contacted by letter. Patients were then followed up by telephone and invited to take part in a face-to-face interview with one or 2 interviewers.

\section{Setting and sample}

A total of 86 participants were identified to take part in the study; 34 refused and attending physicians did not agree for 2 patients to be approached. Interviews took place in setting most convenient to the participant, most frequently in a private area at the hospital (45 patients). A handful of interviews took place in the participant's house (5 patients). On 2 occasions, family members and caregivers were present at the patient's request.

\section{Data collection}

Following informed consent, the interviews were conducted using a semi-structured topic guide, which allowed the interviewers to move between the topics. These were related to exploring (1) first admission and readmissions, (2) length of stay, (3) disease progression, (4) medication, (5) discharge instructions and self-care, (6) social support or lack thereof, and (7) emotional highs and lows. The guide was matched to the study objectives and successfully piloted prior to use (Table 2).

Interviews were recorded, transcribed verbatim and translated into English (when the medium was a different language). Interviews lasted half-an-hour to an hour, and saturation on broad explanatory themes began to emerge about halfway through the scheduled 50 interviews. Repeat interviews were not carried out.

\section{Data analysis and reporting}

Framework analysis was employed. ${ }^{21}$ Researchers familiarised themselves with the data to see if new topics emerged beyond those selected a priori, according to the topics in the interview guide as outlined above; none did. Data were then indexed and organised according to topics using NVivo 11.0 (QSR International, Burlington, US) data management software. Organised data were subsequently charted into an Excel matrix, according to the agreed topics. Line-by-line coding was then applied within the framework, allowing explanatory shared themes to be identified and contrasted between the readmitted and non-readmitted groups. Thematic analysis is reported using illustrative quotes. ${ }^{22}$ All data were double coded, and there were no major discrepancies between coders. Interpretations and minor differences in coding were discussed, and a consensus reached on the meaning of the data.

\section{RESULTS}

\section{Quantitative study}

Table 3 shows the patient characteristics and factors affecting 30-day readmission. Out of 104,496 patients, one-third was aged $30-49(31.2 \%)$ and another one-third 50-69 (32.2\%) years, with readmission rising significantly with increasing age. Majority of the patients were ethnic Chinese $(57.6 \%)$, male and received subsidised care. Other factors that were significantly associated with increased risk of readmission included: discharge destination, increased number of medications upon discharge, and longer inpatient LOS.

Apart from discharge destination, all other factors identified as predictors of 30-day readmission in the bivariate analysis remained significant in the multivariable analysis (Table 4). The strongest predictors of readmission were speciality diagnosis, increased number of medications upon discharge, hospital LOS $>7$ days and subvention class. The odds of readmission were the highest among patients with haematology-oncological malignancy (OR 1.91, 95\% CI 1.70-2.15) as compared to pregnancy, childbirth and puerperium. Although surgical patients had reduced risk of readmission compared to medical patients, the odds of readmission rates increased $(0.55-0.80)$ with higher number of surgical procedures during the index admission. Older age, higher CCI, male sex, higher hospital bill size and Malay ethnicity were also 
Table 1. Patient selection for the qualitative study

\begin{tabular}{|c|c|c|c|}
\hline & & $\begin{array}{l}\text { Readmitted }(n=25) \\
\text { No. }(\%)\end{array}$ & $\begin{array}{l}\text { Non-readmitted }(n=25) \\
\text { No. }(\%)\end{array}$ \\
\hline \multirow[t]{2}{*}{ Sex } & Male & $14(56)$ & $14(56)$ \\
\hline & Female & $11(44)$ & $11(44)$ \\
\hline \multirow[t]{3}{*}{ Age, years } & $19-29$ & $2(8)$ & $1(4)$ \\
\hline & $50-69$ & $13(52)$ & $12(48)$ \\
\hline & 70 and above & $6(24)$ & $7(28)$ \\
\hline \multirow[t]{4}{*}{ Ethnicity } & Chinese & $16(64)$ & $15(60)$ \\
\hline & Malay & $5(20)$ & $6(24)$ \\
\hline & Indian & $2(8)$ & $3(12)$ \\
\hline & Others & $2(8)$ & $1(4)$ \\
\hline \multirow[t]{14}{*}{ Diseases } & $\begin{array}{l}\text { Heart disease (congestive heart failure, chest pain, acute } \\
\text { myocardial infarction and atherosclerotic heart disease) }\end{array}$ & $6(24)$ & $7(28)$ \\
\hline & Respiratory disease (pneumonia and COPD) & $4(16)$ & $4(16)$ \\
\hline & $\begin{array}{l}\text { Cancer (malignant neoplasm of ovary, secondary malignant } \\
\text { neoplasm of liver, lymphoma) }\end{array}$ & $3(12)$ & $1(4)$ \\
\hline & Urinary tract infection & $1(4)$ & $2(8)$ \\
\hline & Cellulitis & $1(4)$ & $1(4)$ \\
\hline & Chronic kidney disease & $1(4)$ & $1(4)$ \\
\hline & Diabetes mellitus & $1(4)$ & $1(4)$ \\
\hline & $\begin{array}{l}\text { Complications of cardiac and vascular prosthetic devices, } \\
\text { implants and grafts }\end{array}$ & $1(4)$ & $1(4)$ \\
\hline & Thyroid nodule, goitre & $1(4)$ & $1(4)$ \\
\hline & Cholecystitis and wound infection following a procedure & $1(4)$ & $1(4)$ \\
\hline & Constipation colic & $1(4)$ & $1(4)$ \\
\hline & Rheumatoid arthritis & $1(4)$ & $1(4)$ \\
\hline & Sleep apnoea & $1(4)$ & $1(4)$ \\
\hline & Haemorrhage and haematoma complicating a procedure & $1(4)$ & $1(4)$ \\
\hline
\end{tabular}

COPD: chronic obstructive pulmonary disease

Fifty patients (25 pairs) were selected for the interview from the readmitted cases in 2016.

In the first stage, age was stratified into 4 groups. The number of pairs of patients needed in each age category was proportional to the total number of patients in each age category in order to represent all ages.

In the second stage, the number of pairs of patients needed in gender was proportionated.

In the last stage, the number of pairs of patients needed in each ethnic group was proportionated in order to represent the ethnic proportions of Chinese,

Malay, Indian and others 
Table 2. Topic guide with illustrative questions and prompts

\begin{tabular}{|c|c|}
\hline Topics & Questions and prompts \\
\hline $\begin{array}{l}\text { 1a. Could you tell me about your first } \\
\text { admission to the hospital in } 2016 \text { ? }\end{array}$ & $\begin{array}{l}\text { Why and how did this admission occurred? } \\
\text { _ Please explain about your first admission }\end{array}$ \\
\hline $\begin{array}{l}\text { 1b. Could you tell me about your } \\
\text { readmission to the hospital? [if } \\
\text { applicable] }\end{array}$ & $\begin{array}{l}\text { Could you tell me why you think you are so frequently readmitted? } \\
-\quad \text { Who made the decision to return to the hospital? (doctor, caregiver, patient) } \\
\text { - } \quad \text { Was there anything you did or did not do that led to readmission? } \\
\text { - } \quad \text { Do you think you did anything that may have made your condition worse? } \\
\text { - } \quad \text { Could you tell me what might have helped prevent having to be readmitted? }\end{array}$ \\
\hline 2. Length of stay & $\begin{array}{l}\text { How many days did you stay in hospital [each time you were admitted as applicable]? } \\
\text { _ } \quad \text { Can you explain more about this experience? }\end{array}$ \\
\hline 3. Disease progression & $\begin{array}{l}\text { When was the disease first diagnosed? } \\
\text { - } \quad \text { Can you tell me about living with this disease being present? }\end{array}$ \\
\hline 4. Medications & $\begin{array}{l}\text { What medication are you taking? } \\
-\quad \text { Can you explain about the instruction that the doctor gave you for taking them? } \\
-\quad \text { Do you take your medications as directed by your physician? Why / why not? } \\
-\quad \text { Did you have any specific problems in being able to obtain the medications that you need? If so, tell } \\
\text { me about it. }\end{array}$ \\
\hline 5. Discharge instructions and self-care & $\begin{array}{l}\text { Please tell me what you remember from your discharge instructions } \\
\text { - } \quad \text { How was it overall? What happened? } \\
\text { - } \quad \text { What arrangements were made for you when you went home? } \\
\text { - } \quad \text { Did you follow all of the discharge instructions? If not, then why? } \\
\text { - } \quad \text { Did you feel able to care for yourself after discharge? Can you tell me why or why not? } \\
\text { - } \quad \text { Can you tell me what you know about taking care of yourself with your current condition; including } \\
\quad \text { healthy dieting? }\end{array}$ \\
\hline 6. Social support/or lack thereof & $\begin{array}{l}\text { Tell me about your social support at home. } \\
\text { - } \quad \text { Did you have proper support once you left the hospital? Can you tell me more about this? } \\
\text { - Did you have any questions about how to care for yourself? How were you able to get the questions } \\
\text { answered? }\end{array}$ \\
\hline 7. Emotional high/lows & $\begin{array}{l}\text { How do you feel after discharged home? } \\
-\quad \text { Please explain your feelings. } \\
\text { How do you feel about staying in hospital? } \\
-\quad \text { What was difficult about it? } \\
-\quad \text { What types of things might have made the experience good, or even better? }\end{array}$ \\
\hline
\end{tabular}

associated with increased readmission rates, in decreasing order of significance.

\section{Qualitative study results}

In the qualitative study, themes are summarised in Table 5 alongside illustrative quotes. Some repeated themes emerged as frequently shared across both the non-readmitted and the readmitted patients; others were unique to each group. Both groups generally expressed that they had adequate home support after discharge; although the participants in the non-readmitted group imparted a stronger sense of self-efficacy, for example by suggesting that they were prepared and able to take care of themselves after discharge-such statements did not emerge from the readmitted patients' accounts. Having adequate financial resources to access health services was also mostly expressed as a shared experience, although some readmitted patients mentioned lack of resources as a reason for missing medical follow-ups. Proper discharge instructions were often reported to be given to both groups; while reporting compliance to medical appointments, but less so to medication, was also an experience that was equally shared across both groups. In both groups, patients who admitted nonadherence said they did so because they were too busy or that they simply forgot.

On the other hand, the readmitted group reported having more negative emotions related to the patient role; or feeling powerless and hopeless over their condition. They also reported feeling like a burden in the wards and "left out" of care and treatment decisions. A repeated, dominant theme was also identified in this group around feeling that the wrong medicine or ineffective treatment was being given. These 
Table 3. Patient characteristics by readmission status

\begin{tabular}{|c|c|c|c|}
\hline \multirow{2}{*}{ Factors } & & \multicolumn{2}{|c|}{ Readmission within 30 days } \\
\hline & $\begin{array}{c}\text { Total } \\
(\mathrm{N}=104,496)\end{array}$ & Readmitted $(\mathrm{n}=\mathbf{8 , 9 8 2})$ & $\begin{array}{c}\text { Non-readmitted } \\
\quad(n=95,514)\end{array}$ \\
\hline \multicolumn{4}{|l|}{ Age years, no. $(\%)^{\mathrm{a}}$} \\
\hline $18-29$ & $18,818(18.0)$ & $991(11.03)$ & $17,827(18.66)$ \\
\hline $30-49$ & $32,608(31.2)$ & 2,074 (23.09) & $30,534(31.97)$ \\
\hline $50-69$ & $33,695(32.2)$ & $3,494(38.90)$ & $30,201(31.62)$ \\
\hline$\geq 70$ & $19,375(18.5)$ & $2,423(26.98)$ & $16,952(17.75)$ \\
\hline \multicolumn{4}{|l|}{ Sex, no. $(\%)^{\mathrm{a}}$} \\
\hline Male & $51,867(49.6)$ & $4,694(52.3)$ & $47,173(49.4)$ \\
\hline Female & $52,629(50.4)$ & $4,288(47.7)$ & $48,341(50.6)$ \\
\hline \multicolumn{4}{|l|}{ Ethnicity, no. $(\%)^{\mathrm{a}}$} \\
\hline Chinese & $60,168(57.6)$ & $5,481(61.0)$ & $54,687(57.3)$ \\
\hline Indian & $13,388(12.8)$ & $893(9.9)$ & $12,495(13.1)$ \\
\hline Malay & $14,746(14.1)$ & $1,401(15.6)$ & $13,345(14.0)$ \\
\hline Others & $16,194(15.5)$ & $1,207(13.4)$ & $14,987(15.7)$ \\
\hline \multicolumn{4}{|l|}{ Patient class, no. $(\%)^{\mathrm{a}}$} \\
\hline Private & $41,014(39.3)$ & $2,528(28.2)$ & $38,486(40.3)$ \\
\hline Subsidised & $63,482(60.8)$ & $6,454(71.9)$ & $57,028(59.7)$ \\
\hline \multicolumn{4}{|c|}{ Discharge destination, no. $(\%)^{\mathrm{a}}$} \\
\hline Home & $99,205(94.9)$ & $8,341(92.9)$ & $90,864(95.1)$ \\
\hline Stepdown care facility & $5,291(5.1)$ & $641(7.1)$ & $4,650(4.9)$ \\
\hline \multicolumn{4}{|c|}{ Number of surgical operation, no. $(\%)^{\mathrm{a}}$} \\
\hline 0 & $52,098(49.9)$ & $4,998(55.6)$ & $47,100(49.3)$ \\
\hline 1 & $43,127(41.3)$ & $2,765(30.8)$ & $40,362(42.3)$ \\
\hline 2 & $6,302(6.0)$ & $778(8.7)$ & $5,524(5.8)$ \\
\hline$\geq 3$ & $2,969(2.8)$ & $441(4.9)$ & $2,528(2.7)$ \\
\hline \multicolumn{4}{|c|}{ Length of stay, days, no. $(\%)^{a}$} \\
\hline $1-7$ & $86,984(83.2)$ & $6,272(69.8)$ & $80,712(84.5)$ \\
\hline$>7$ & $17,512(16.8)$ & $2,710(30.2)$ & $14,802(15.5)$ \\
\hline \multicolumn{4}{|c|}{ Number of discharge medication, no. $(\%)^{\mathrm{a}, \mathrm{b}}$} \\
\hline $0-4$ & $39,615(39.5)$ & $2,196(26.0)$ & $37,419(40.8)$ \\
\hline $5-10$ & $46,970(46.9)$ & $4,027(47.7)$ & $42,943(46.8)$ \\
\hline$\geq 11$ & $13,668(13.6)$ & $2,225(26.3)$ & $11,443(12.5)$ \\
\hline \multicolumn{4}{|c|}{ Charlson Comorbidity Index, no. $(\%)^{\mathrm{a}}$} \\
\hline $0-3$ & $83,355(79.8)$ & $5,696(63.4)$ & $77,659(81.3)$ \\
\hline $4-7$ & $17,681(16.9)$ & $2,529(28.2)$ & $15,152(15.9)$ \\
\hline$\geq 8$ & $3,460(3.3)$ & $757(8.4)$ & $2,703(2.8)$ \\
\hline
\end{tabular}


Table 3. Patient characteristics by readmission status (Cont'd)

\begin{tabular}{|c|c|c|c|}
\hline \multirow[t]{2}{*}{ Factors } & & \multicolumn{2}{|c|}{ Readmission within 30 days } \\
\hline & $\begin{array}{c}\text { Total } \\
(\mathrm{N}=\mathbf{1 0 4 , 4 9 6 )}\end{array}$ & Readmitted $(\mathrm{n}=8,982)$ & $\begin{array}{c}\text { Non-readmitted } \\
(n=95,514)\end{array}$ \\
\hline \multicolumn{4}{|c|}{ Number of visit to emergency department in past 12 months, no. $(\%)^{a}$} \\
\hline 0 & $27,707(26.5)$ & $2,628(29.3)$ & $25,079(26.3)$ \\
\hline 1 & $64,781(62.0)$ & $5,195(57.8)$ & $59,586(62.3)$ \\
\hline 2 & $9,184(8.8)$ & $889(9.9)$ & $8,295(8.7)$ \\
\hline 3 & $1,885(1.8)$ & $186(2.1)$ & $1,699(1.8)$ \\
\hline$\geq 4$ & $939(0.9)$ & $84(0.9)$ & $855(0.9)$ \\
\hline \multicolumn{4}{|l|}{ Hospital bill, SGD, no.' (\%) } \\
\hline$<2,000$ & $25,049(24.0)$ & $1,942(21.6)$ & $23,107(24.2)$ \\
\hline 2,000 to $<4,000$ & $23,613(22.6)$ & $1,603(17.8)$ & $22,010(23.0)$ \\
\hline 4,000 to $<6,000$ & $16,107(15.4)$ & $1,138(12.7)$ & $14,969(15.7)$ \\
\hline 6,000 to $<8,000$ & $9,916(9.5)$ & $729(8.1)$ & $9.187(9.6)$ \\
\hline 8,000 to $<10,000$ & $5,819(5.6)$ & $551(6.1)$ & $5,268(5.5)$ \\
\hline$\geq 10,000$ & $23,992(23.0)$ & 3,019 (33.6) & $20,973(22.0)$ \\
\hline \multicolumn{4}{|l|}{ Diagnosis groups, no. $(\%)^{\mathrm{a}}$} \\
\hline Others & $21,920(21.0)$ & $1,369(15.2)$ & $20,551(21.5)$ \\
\hline Circulatory system & $15,446(14.8)$ & $1,826(20.3)$ & $13,620(14.3)$ \\
\hline Injury, poisoning and external causes & $14,699(14.1)$ & $758(8.4)$ & $13.941(14.6)$ \\
\hline Pregnancy, childbirth and puerperium & $13,065(12.5)$ & $830(9.2)$ & $12,235(12.8)$ \\
\hline Neoplasms and diseases of blood & $9,763(9.3)$ & $1,923(21.4)$ & $7.840(8.2)$ \\
\hline Digestive system & $8,947(8.6)$ & $716(8.0)$ & $8,231(8.6)$ \\
\hline Respiratory system & $6,470(6.2)$ & $490(5.5)$ & $5,980(6.3)$ \\
\hline Genitourinary system & $5,287(5.1)$ & $384(4.3)$ & $4,903(5.1)$ \\
\hline Nervous system & $3,921(3.8)$ & $277(3.1)$ & $3,644(3.8)$ \\
\hline Endocrine and metabolic diseases & $3,469(3.3)$ & $358(4.0)$ & $3,111(3.3)$ \\
\hline Eye, adnexa, ear and mastoid process & $1,509(1.4)$ & $51(0.6)$ & $1,458(1.5)$ \\
\hline
\end{tabular}

SGD: Singapore dollar ${ }^{\mathrm{a}}$

Significant at $P<0.001$

${ }^{\mathrm{b}}$ Information available for only 100,253 patients

patients shared their frustration that the medication given took a long time to take effect, which may have contributed to non-compliance. The readmitters also often described having less knowledge and/or compliance to healthy diet.

\section{DISCUSSION}

Our study highlighted that hospital readmission is a complex process with a wide range of contributing factors. Disease category was the highest risk factor of readmission. Increasing age and number of 
Table 4. Significant predictors of 30-day readmission in the multivariable logistic regression

\begin{tabular}{|c|c|c|}
\hline Characteristics & Subgroup & Adjusted 30-day readmission rate OR $(95 \% \mathrm{CI})$ \\
\hline \multirow[t]{10}{*}{ Diagnosis groups } & Pregnancy, childbirth and puerperium & Ref \\
\hline & Neoplasms and diseases of blood & $1.91(1.70-2.15)^{\mathrm{a}}$ \\
\hline & Digestive system & $0.84(0.74-0.96)^{\mathrm{a}}$ \\
\hline & Circulatory system & $0.83(0.73-0.93)^{\mathrm{a}}$ \\
\hline & Endocrine and metabolic diseases & $0.70(0.60-0.81)^{\mathrm{a}}$ \\
\hline & Genitourinary system & $0.65(0.56-0.76)^{\mathrm{a}}$ \\
\hline & Nervous system & $0.52(0.44-0.62)^{\mathrm{a}}$ \\
\hline & Others & $0.51(0.45-0.57)^{\mathrm{a}}$ \\
\hline & Respiratory system & $0.50(0.43-0.58)^{\mathrm{a}}$ \\
\hline & Eye, adnexa, ear and mastoid process & $0.28(0.21-0.38)^{\mathrm{a}}$ \\
\hline \multirow[t]{3}{*}{ Number of discharge medication } & $0-4$ & Ref \\
\hline & $5-10$ & $1.21(1.14-1.29)^{\mathrm{a}}$ \\
\hline & $\geq 11$ & $1.80(1.66-1.95)^{\mathrm{a}}$ \\
\hline \multirow[t]{2}{*}{ Length of stay, days } & $1-7$ & 1.00 \\
\hline & $>7$ & $1.46(1.36-1.58)^{\mathrm{a}}$ \\
\hline \multirow[t]{2}{*}{ Patient class } & Private & Ref \\
\hline & Subsidised & $1.42(1.34-1.51)^{\mathrm{a}}$ \\
\hline \multirow[t]{3}{*}{ Age group, years } & $18-29$ & Ref \\
\hline & $50-69$ & $1.35(1.23-1.48)^{\mathrm{a}}$ \\
\hline & $\geq 70$ & $1.43(1.29-1.58)^{\mathrm{a}}$ \\
\hline \multirow{5}{*}{$\begin{array}{l}\text { Number of visits to emergency department } \\
\text { in past } 12 \text { months }\end{array}$} & 0 & Ref \\
\hline & 1 & $0.91(0.85-0.97)^{\mathrm{a}}$ \\
\hline & 2 & $1.22(1.11-1.34)^{\mathrm{a}}$ \\
\hline & 3 & $1.35(1.13-1.60)^{\mathrm{a}}$ \\
\hline & $\geq 4$ & $1.31(1.02-1.66)^{\mathrm{a}}$ \\
\hline \multirow[t]{3}{*}{ Charlson Comorbidity Index } & $0-3$ & Ref \\
\hline & $4-7$ & $1.25(1.17-1.32)^{\mathrm{a}}$ \\
\hline & $\geq 8$ & $1.29(1.16-1.43)^{\mathrm{a}}$ \\
\hline \multirow[t]{6}{*}{ Hospital bill, SGD } & $<2,000$ & Ref \\
\hline & 2,000 to $<4,000$ & $0.96(0.89-1.04)$ \\
\hline & 4,000 to $<6,000$ & $1.04(0.95-1.13)$ \\
\hline & 6,000 to $<8,000$ & $0.98(0.88-1.09)$ \\
\hline & 8,000 to $<10,000$ & $1.17(1.04-1.32)^{\mathrm{a}}$ \\
\hline & $\geq 10,000$ & $1.18(1.06-1.32)^{\mathrm{a}}$ \\
\hline
\end{tabular}


Table 4. Significant predictors of 30-day readmission in the multivariable logistic regression (Cont'd)

\begin{tabular}{|c|c|c|}
\hline Characteristics & Subgroup & Adjusted 30-day readmission rate $\mathrm{OR}(95 \% \mathrm{CI})$ \\
\hline \multirow[t]{4}{*}{ Ethnicity } & Chinese & Ref \\
\hline & Indian & $0.95(0.88-1.04)$ \\
\hline & Malay & $1.10(1.03-1.18)^{\mathrm{a}}$ \\
\hline & Others & $1.04(0.97-1.13)$ \\
\hline \multirow[t]{2}{*}{ Sex } & Female & Ref \\
\hline & Male & $1.17(1.12-1.23)^{\mathrm{a}}$ \\
\hline \multirow[t]{4}{*}{ Number of surgical operations } & 0 & Ref \\
\hline & 1 & $0.55(0.51-0.58)^{\mathrm{a}}$ \\
\hline & 2 & $0.74(0.67-0.82)^{\mathrm{a}}$ \\
\hline & $\geq 3$ & $0.80(0.71-0.91)^{\mathrm{a}}$ \\
\hline
\end{tabular}

CI: confidence interval; OR: odds ratio; Ref: reference; SGD: Singapore dollar

a Significant at $P<0.05$

comorbidities can be related but also predicted readmissions independently. Similarly, number of medications used and frequent visits to the emergency department are markers of disease burden and high healthcare utilisation, respectively, which were independently associated with readmission. Patients destined for readmission had longer LOS and higher hospital bill size, therefore likely opted for government subvention during their index admissions.

Some of the risk factors in our study are common with the previous literature. In the HOSPITAL score study, LOS during the index admission and discharge from oncological services were associated with higher risks of readmission, ${ }^{10}$ which was similar to our investigation. We found that the number of emergency department visits in preceding 12 months was associated with readmission while Donze et al. established that the number of inpatient hospital admissions during similar duration was predictive. ${ }^{10}$ LACE index also included variables like LOS, CCI and emergency visit in previous 6 months, which was consistent with our study. ${ }^{9}$ However, we identified additional factors including age, medical versus surgical admissions, number of operations and number of discharge medications to be also independently associated with readmission.

One important aspect of the current study is the inclusion of qualitative data from patients' interviews. Analyses revealed shared experiences of medicine adherence, self-care upon discharge, and social support by admitted and readmitted patients. Overall, finances were often not a barrier to care-seeking for either. Notable and emphatic differences between patient accounts were around their hospitalisation experiences, and respective positive versus negative internalisation of the "patient role" (i.e. self-efficacy in recovery versus feeling like a burden). This negative self-concept appeared in turn to be connected to readmitted patients' feeling of being less involved in their treatment, decision-making and that the "wrong" treatment was being administered. This narrative suggests a profile of readmitted patients that fits with more complex medical cases, and those undergoing multiple operations, overlapping with a lack of empowerment to participate in treatment options. Our qualitative analysis suggests a complex set of dynamics that underpins the clinical assumptions around adherence and clinical follow-through after discharge.

During the interpretation stage of the mixed methodology of the project, we find integration in the quantitative outcomes and qualitative experience of the patients. The quantitative data identify patients with chronic diseases (cardiovascular, respiratory and endocrine-related diseases) to have higher odds of readmissions. Typical markers of chronic disease population include elderly age, frequent emergency department visits, longer LOS and increased number of discharge medications. It is understandable that some of these patients feel frustrated and believe that medications are either not working or wrongly given. Similar findings were observed in a qualitative study of elderly patients readmitted to an Australian hospital who expressed feeling of neglect in care, lack of knowledge-sharing and being given mixed messages in relation to the outcome. ${ }^{15}$ During the interview, readmitted patients expressed inability to control their 


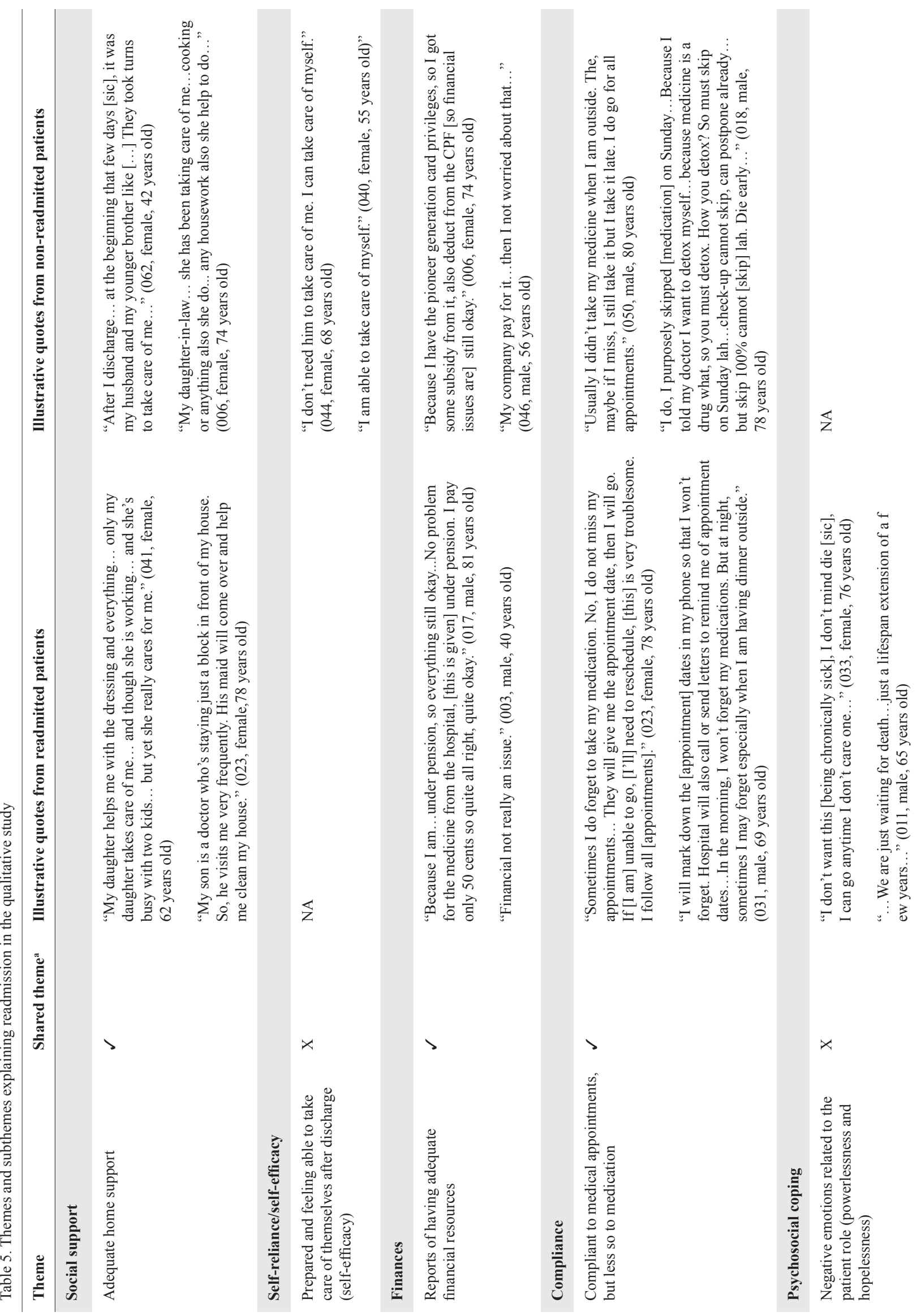




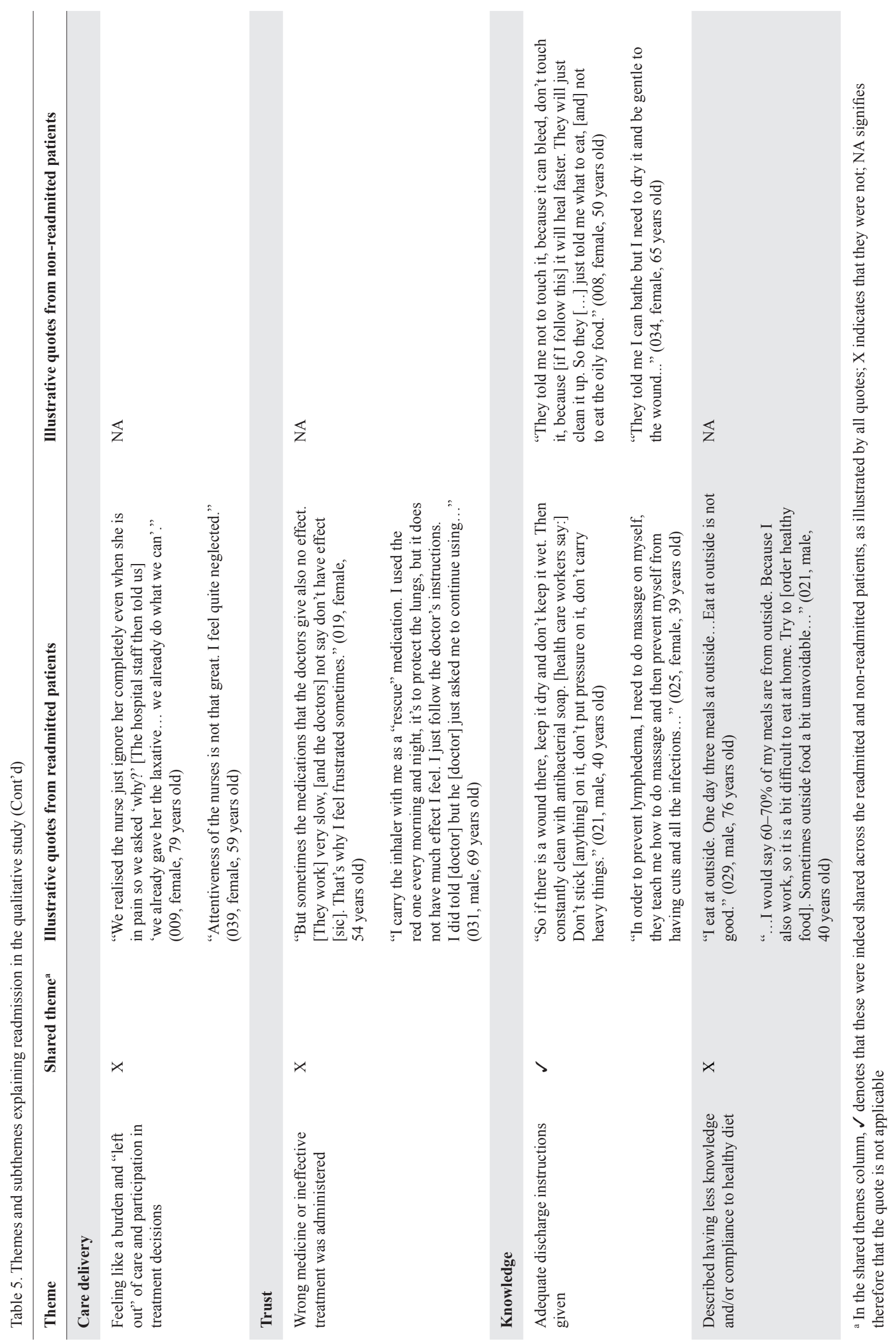


disease and a feeling of powerlessness and ineffective treatment, which again characterises the vulnerable chronic disease cohort. In addition, frequent readmission may lead to feelings of being ignored by hospital staff and family, lack of positive experience in hospital, and being excluded from the management decisions.

Readmission analysis models have been largely used for 2 distinct purposes. Government and authorities often use a risk-standardised readmission rates for comparing hospitals, reporting and reimbursement. ${ }^{23}$ A further use of readmission model is to identify high-risk patients where intervention may reduce the risk. To be effective, the latter models should include variables that are easily available and have discriminatory power to differentiate different risk groups. Since interventions to reduce readmissions take time to implement, ideally such variables should be available in the early stage of index admission. ${ }^{23,24}$ In the current study, many variables in our model are easily obtained from the demographic profiles, comorbidities and past histories. This is in contrast with previous studies that used variables recorded only on the discharge day. ${ }^{25}$ All adult patients, including those admitted under the surgical disciplines, were covered in our study whereas previous literature included mainly medical patients. ${ }^{6,7}$ Documentation of patient's perspective by qualitative data is uncommon in previous database analysis. Our patients' views elicited unique features in readmitted patients; this information should interest clinicians, administrators and policymakers.

Several limitations of the study are worth mentioning. Firstly, the current study comprises data collected within a single academic centre and thus need to be validated in other institutions. We could not collect data from other hospitals, which may potentially dilute the true hospital readmission rate if patients were readmitted to another hospital. Such extensive administrative data need extended period of data curation; therefore, we could not include more recent data. Finding actionable variables in the model was not the aim of the study as the interventions leading to improvement in readmission rates are generally multistep and complex. A metaanalysis found that interventions with at least 5 components, involving more individuals in care delivery (at least 2), and supporting patient capacity for self-care were more effective. ${ }^{26}$ Larger social and environmental factors like status of primary care, ease of access to healthcare and functional status of the patient at discharge may also contribute to the readmission. Hospital and health system-related factors are mostly not captured in the current models, despite their influence on readmissions. These may include availability of hospital bed, ${ }^{27}$ early follow-up, ${ }^{28}$ effective medicine reconciliation ${ }^{29}$ and inpatient quality of care. ${ }^{30}$ Such data may not be easily available and although could improve the predictive power of the model, including them in the risk-standardisation model removes the very deficits that hospitals strive to improve by quality initiatives. ${ }^{11}$

\section{CONCLUSION}

Unplanned readmission is often seen as a separate singular event. It is, however, complex, and our study identified several factors related to patient (e.g. diagnosis, age, sex, ethnicity, comorbidity, subvention, visit to emergency department), procedure/medical (e.g. number of surgeries, number of discharge medications), and hospital (e.g. LOS, bill size) to be associated. Qualitative data elicited the vulnerability of readmitted patients, their negative emotions, and feeling of uselessness to the family and society at large. Understanding that discharged patients may remain in vulnerable health conditions, both physically and psychologically even after their hospital stay-a phenomenon termed "post-hospital syndrome"-is an important aspect of the changed healthcare scenario. Unless sufficient support is given to these patients, inability to cope with the burden of discharge may lead to readmissions. ${ }^{26}$ Potential areas were identified for improvement, such as non-adherence to medical advice, involving patients in their care, and imparting knowledge about their disease condition and treatment.

\begin{abstract}
Acknowledgements
We would like to thank the Academic Informatics Office, National University Health System for data extraction. We also thank the participants of the interviews for their generous participation. The study was funded by the Centre for Health Services and Policy Research $2^{\text {nd }}$ Seed Funding 2015.
\end{abstract}

\section{REFERENCES}

1. Hasan O, Meltzer DO, Shaykevich SA, et al. Hospital readmission in general medicine patients: A prediction model. J Gen Intern Med 2010;25:211-9.

2. Yam $\mathrm{CH}$, Wong EL, Chan FW, et al. Avoidable readmission in Hong Kong--system, clinician, patient or social factor? BMC Health Serv Res 2010;10:311.

3. Blunt I, Bardsley M, Grove A, et al. Classifying emergency 30-day readmissions in England using routine hospital data 2004-2010: What is the scope for reduction? Emerg Med J 2015;32:44-50. 
4. Campione JR, Smith SA, Mardon RE. Hospital-level factors related to 30-day readmission rates. Am J Med Qual 2017;32:48-57.

5. Low LL, Liu N, Ong MEH, et al. Performance of the LACE index to identify elderly patients at high risk for hospital readmission in Singapore. Medicine (Baltimore) 2017;96:e6728.

6. Low LL, Lee KH, Hock Ong ME, et al. Predicting 30-day readmissions: Performance of the LACE index compared with a regression model among general medicine patients in Singapore. Biomed Res Int 2015;2015:169870.

7. Tan SY, Low LL, Yang Y, et al. Applicability of a previously validated readmission predictive index in medical patients in Singapore: A retrospective study. BMC Health Serv Res 2013; 13:366.

8. Wee S, Low S, Rao K, et al. Factors associated with hospital readmission and emergency visits among older adults-5-year experience in a busy acute hospital. J Clin Gerontol 2018;9:126-36.

9. van Walraven C, Dhalla IA, Bell C, et al. Derivation and validation of an index to predict early death or unplanned readmission after discharge from hospital to the community. CMAJ 2010;182:551-7.

10. Donzé J, Aujesky D, Williams D, et al. Potentially avoidable 30-day hospital readmissions in medical patients: Derivation and validation of a prediction model. JAMA Intern Med 2013; $173: 632-8$

11. Kansagara D, Englander H, Salanitro A, et al. Risk prediction models for hospital readmission: A systematic review. JAMA 2011;306:1688-98

12. Rubin DJ, Donnell-Jackson K, Jhingan R, et al. Early readmission among patients with diabetes: A qualitative assessment of contributing factors. J Diabetes Complications 2014;28:869-73.

13. Hodges P. Factors impacting readmissions of older patients with heart failure. Crit Care Nurs Q 2009;32:33-43.

14. Leventhal MJE, Riegel B, Carlson B, et al. Negotiating compliance in heart failure: Remaining issues and questions. Eur $\mathrm{J}$ of Cardiovas Nurs 2005;4:298-307.

15. Dilworth S, Higgins I, Parker V. Feeling let down: An exploratory study of the experiences of older people who were readmitted to hospital following a recent discharge. Contemp Nurse 2012; 42:280-8.

16. Creswell JW, Creswell JD. Research design: Qualitative, quantitative, and mixed methods approaches. SAGE Publications; 2014.
17. Sciences NOoBaS. Best practices for mixed methods research in the health sciences, 2018. (2nd ed.) U.S. Department of Health and Human Services, National Institutes of Health.

18. Peduzzi P, Concato J, Feinstein AR, et al. Importance of events per independent variable in proportional hazards regression analysis. II. Accuracy and precision of regression estimates. J Clin Epidemiol 1995;48:1503-10.

19. Tong A, Craig J, Sainsbury P. Consolidated criteria for reporting qualitative research (COREQ): A 32-item checklist for interviews and focus groups. Int J Qual Health Care 2007;19:349-57.

20. King N, Horrocks C. Interviews in qualitative research. Los Angeles: SAGE; 2010.

21. Ritchie J, Lewis J, Nicholls C, et al. Qualitative research practice: A guide for social science students and researchers. London: SAGE; 2013.

22. Guest G, MacQueen KM, Namey EE. Applied thematic analysis. SAGE; 2012

23. Coleman EA, Parry C, Chalmers S, et al. The care transitions intervention: Results of a randomized controlled trial. Arch Intern Med 2006;166:1822-8.

24. Jack BW, Chetty VK, Anthony D, et al. A reengineered hospital discharge program to decrease rehospitalization: A randomized trial. Ann Intern Med 2009;150:178-87.

25. Donzé J, Lipsitz S, Bates DW, et al. Causes and patterns of readmissions in patients with common comorbidities: Retrospective cohort study. BMJ 2013;347:f7171.

26. Leppin AL, Gionfriddo MR, Kessler M, et al. Preventing 30-day hospital readmissions: A systematic review and meta-analysis of randomized trials. JAMA Intern Med 2014;174:1095-107.

27. Fisher E, Goodman D, Skinner J, et al. Health care spending, quality, and outcomes: More isn't always better. 2009.

28. Hernandez AF, Greiner MA, Fonarow GC, et al. Relationship between early physician follow-up and 30-day readmission among medicare beneficiaries hospitalized for heart failure. JAMA 2010;303:1716-22.

29. Kripalani S, Jackson AT, Schnipper JL, et al. Promoting effective transitions of care at hospital discharge: A review of key issues for hospitalists. J Hosp Med 2007;2:314-23.

30. Weissman JS, Ayanian JZ, Chasan-Taber S, et al. Hospital readmissions and quality of care. Med Care 1999:490-501. 